\title{
Anaerobic Co-Digestion of Pig and Cow Manure with a Solar Dried Mixture of Food Waste and Olive Mill Wastewater ${ }^{\dagger}$
}

\author{
Nikolaos Papastefanakis 1,2,*, Chryssa Bouki 2,3, Michail S. Fountoulakis ${ }^{1}$, Christos Tsompanidis ${ }^{2}$, \\ Theofanis Lolos ${ }^{2}$, Nikolaos Zotos ${ }^{4}$, Nikitas Mavrakis ${ }^{5}$ and Thrassyvoulos Manios ${ }^{3}$ \\ 1 Department of Environment, University of the Aegean, 81100 Mytilene, Greece; \\ fountoulakis@env.aegean.gr \\ 2 Enviroplan S.A., 23 Perikleous \& Iras Str, 15344 Gerakas Athens, Greece; cbouki@hmu.gr (C.B.); \\ ct@enviroplan.gr (C.T); fl@enviroplan.gr (T.L.) \\ 3 Laboratory of Solid Waste \& Wastewater Management, Department of Agriculture, Hellenic \\ Mediterranean University, 71410 Heraklion, Greece; tmanios@hmu.gr \\ 4 Future Intelligence Ltd., 15341 Athens, Greece; nzotos@f-in.gr \\ 5 TIERRA O.E., 71202 Irakleio, Greece; mavrakis@tierra.gr \\ * Correspondence: nikos.papastefanakis@yahoo.gr \\ † Presented at TERRAenVISION 2019, Barcelona, Spain, 2-7 September 2019. \\ Published: 23 June 2020
}

\begin{abstract}
Biogas production through anaerobic digestion is a well-established practice worldwide combining waste treatment and energy production at the same time. One of the challenges of this technology is to increase the yield of biogas production and secure the disposal of the effluent of anaerobic reactors. It is well known that various organic residues such as cheese whey, olive mill wastewater, as well as food waste from hotel units, could be combined with other materials (animal manures, sewage sludge, etc.) in order to increase biogas production through co-digestion. However, their high seasonal variation and high transport costs is a barrier for their use. Solar drying process can be a very attractive technology for volume reduction in order to decrease the storage and the transportation cost. Moreover using solar energy may well be an alternative solution for reduction of drying process costs. In this study, co-digestion of pig manure (PM) and cow manure (CM) with solar dried mixture of food waste (FW) and olive mill wastewater (OMW), named as biobooster, was studied in an attempt to improve biogas production of existing on -farms plants which co-digest manure with other farm waste. The effect of biobooster in biogas production was investigated using three lab-scale continuous stirred-tank reactors (CSTR) (3 L working volume) (D1-D3) under mesophilic conditions $\left(37 \pm 2^{\circ} \mathrm{C}\right)$ with a hydraulic retention time of 20 days. Initially, all reactors were inoculated with anaerobic sludge originating from sewage treatment plant of the city of Heraklion, and contained $19.6 \mathrm{~g} / \mathrm{L}$ TS, $10.8 \mathrm{~g} / \mathrm{L} \mathrm{VS}$ and $17.5 \mathrm{~g} / \mathrm{L}$ COD. Three types of influent feedstock were utilized: D1: PM $(95 \%)+$ CM (5\%) (VSin = $33.58 \pm 4.51 \mathrm{~g} / \mathrm{L}), \mathrm{D} 2: \mathrm{PM}(95 \%)+$ $\mathrm{CM}(5 \%)+$ Biobooster $(1 \%)(\mathrm{VSin}=41.07 \pm 7.16 \mathrm{~g} / \mathrm{L}), \mathrm{D} 3: \mathrm{PM}(100 \%)+$ Biobooster $(1 \%)(\mathrm{VSin}=8.48 \pm$ $0.87 \mathrm{~g} / \mathrm{L}$ ). The experiments showed that the addition of biobooster to pig and cow manure significantly increased biogas production by nearly $65 \%$ as value of $662.75 \pm 172.50 \mathrm{~mL} / \mathrm{l} / \mathrm{d}$ compared to that with pig and cow manure alone $(402.60 \pm 131.89 \mathrm{~mL} / \mathrm{l} / \mathrm{d})$. The biogas production in $\mathrm{D} 3$ reactor was $242.50 \pm 56.82 \mathrm{~mL} / \mathrm{l} / \mathrm{d}$. This work suggests that methane can be improved very efficiently by adding a small portion ( $20 \%$ increase of VS) of dried agro-industrial by-products in the inlet of digesters of existing on - farms plants.
\end{abstract}

Keywords: anaerobic co-digestion; solar drying; pig manure; caw manure; food waste; olive mill wastewater 
Acknowledgments: This research has been co-financed by the European Union and Greek national funds through the Operational Program Competitiveness, Entrepreneurship and Innovation, under the call RESEARCH-CREATE-INNOVATE (project code: T1EDK-02460).

(C) 2020 by the authors. Licensee MDPI, Basel, Switzerland. This article is an open access article distributed under the terms and conditions of the Creative Commons Attribution (CC BY) license (http://creativecommons.org/licenses/by/4.0/). 